\title{
Allegations prompt Manitoba pathology probes
}

Published at www.cmaj.ca on Dec. 16, 2009

$\mathrm{M}$ anitoba's pathology system is under scrutiny for the second time in two years following new allegations of mismanagement, financial irregularities and hostile working conditions.

A "toxic and hostile" work environment is affecting the quality of the work at Diagnostic Services Manitoba, the provincial agency that oversees publicly funded laboratories, stated former Health Sciences Centre pathologist Dr. David Grynspan in a report that was submitted to the nonprofit corporation in November 2009 and subsequently released to the health critic from the Manitoba Progressive Conservative Party and made public in early December 2009.

Grynspan also alleged that much of the conflict and discord was created when senior managers at the Diagnostic Services Manitoba lab started hoarding low-complexity cases to collect fee-forservice payments on top of their salaries. The arrangement led to shoddy work as pathologists tried to process large volumes of low-complexity cases for extra payment, Grynspan alleged, adding that it also put undue stress on the entire agency.

With managers sequestering lowcomplexity cases to collect extra fees, pathologists who do not take on the piecemeal work are left with larger numbers of high-complexity cases that take more time and put pathologists under more stress, the report states.

Grynspan went public with his report because he is concerned the problem is not being taken seriously within Diagnostic Services Manitoba and that managers are discouraging other pathologists from coming forward. "It's all being managed in bad faith," he says. "This was a question of integrity for me."

Of the 46 pathology positions at the agency, there are currently eight vacancies. Grynspan says more pathologists are preparing to leave to escape the working conditions. "There are quite a

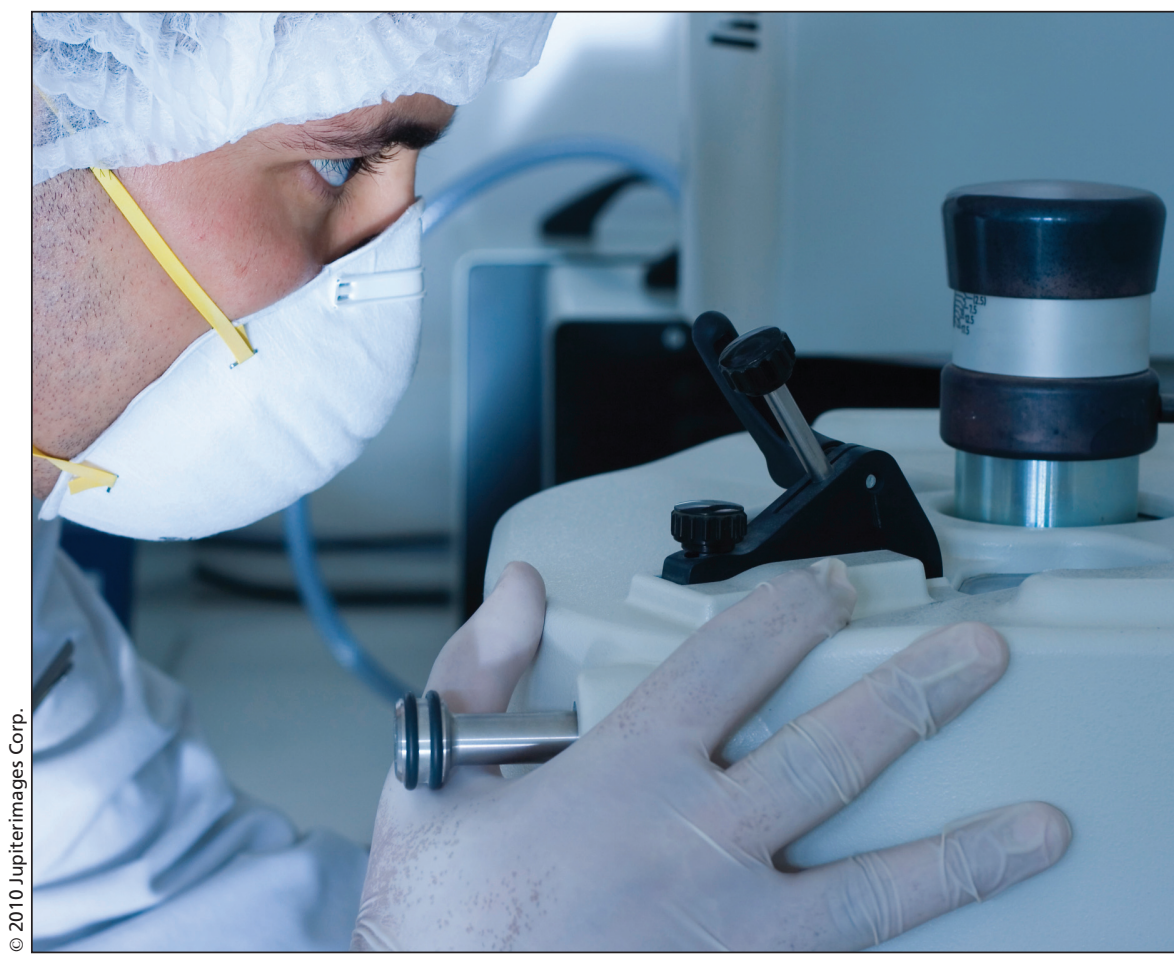

Diagnostic Services Manitoba has ordered two reviews of its operations after a pathologist alleged that current working conditions are "toxic and hostile."

few people who just cannot put up with the hostility any more."

The Grynspan report is the latest chapter in a national tale about quality and capacity errors within Canada's pathology system (CMAJ 2008; 10 .1503/cmaj.080925). In 2008, several provinces suffered scandals involving botched pathology results, including Newfoundland, New Brunswick and Ontario.

Last year, Manitoba undertook a high-profile review of the work of Dr. Robert Stark, a senior pathologist at St. Boniface General Hospital. A detailed review of his cases uncovered significant errors in 40 cases, including two where the patients, both of whom had cancer, received the wrong diagnosis based on Stark's analysis.

In response to Grynspan's report, Diagnostic Services Manitoba has ordered two separate reviews, one internal and the other by an external committee of experts. The latter will be led by Dr. Sharon Macdonald, head of community health services at the University of Manitoba's faculty of medicine.

Macdonald says the internal review will collect feedback from all the individuals named in the report and others who were not named but who might have important insight into the allegations. That information will go to the external review committee, which will conduct a more thorough investigation and prepare recommendations for ways to improve the system, she says.

"We do have the ability to offer recommendations and suggestions," Macdonald says. "Most importantly, though, the (Diagnostic Services Manitoba) board needs to have feedback about these allegations." - Dan Lett, Winnipeg, Man.

DOI:10.1503/cmaj.109-3138 